\title{
Article \\ Evaluation of Hepatic Biochemical Parameters during Antiviral Treatment in COVID-19 Patients
}

\author{
Felicia Marc ${ }^{1}$, Corina Moldovan ${ }^{1}$, Anica Hoza ${ }^{1}$, Patricia Restea ${ }^{1}$, Liliana Sachelarie ${ }^{2, *(\mathbb{D} \text {, }}$ \\ Laura Ecaterina Romila ${ }^{2, *}$, Corina Suteu ${ }^{1}$ and Dorina Maria Farcas ${ }^{1}$ \\ 1 Clinical Departament, Faculty of Medicine, Oradea University, 410610 Oradea, Romania; \\ feliciamarc.dr@gmail.com (F.M.); cmold2003@yahoo.com (C.M.); anica_hoza@yahoo.com (A.H.); \\ resteapatri@yahoo.com (P.R.); suteucorina@gmail.com (C.S.); dmfarcas@yahoo.com (D.M.F.) \\ 2 Preclinical Department, Apollonia University, 700535 Iasi, Romania \\ * Correspondence: lisachero@yahoo.com (L.S.); laura_ekaa@yahoo.com (L.E.R.)
}

Citation: Marc, F.; Moldovan, C.; Hoza, A.; Restea, P.; Sachelarie, L.; Romila, L.E.; Suteu, C.; Farcas, D.M Evaluation of Hepatic Biochemical Parameters during Antiviral Treatment in COVID-19 Patients. Biology 2022, 11, 13. https://doi.org/ $10.3390 /$ biology11010013

Academic Editors

Mohamad Goldust, Robert

A. Schwartz, Dedee Murrell, Torello Lotti and Tomas Majtan

Received: 3 November 2021

Accepted: 21 December 2021

Published: 23 December 2021

Publisher's Note: MDPI stays neutral with regard to jurisdictional claims in published maps and institutional affiliations.

Copyright: (C) 2021 by the authors. Licensee MDPI, Basel, Switzerland. This article is an open access article distributed under the terms and conditions of the Creative Commons Attribution (CC BY) license (https:// creativecommons.org/licenses/by/ $4.0 /)$.
Simple Summary: In order to treat COVID-19 disease, various drugs have been used as repurposed drugs, because no drug directly targets against the SARS-CoV-2 virus. The aim of this study was to evaluate the relationship between the drugs used for COVID-19 treatment and liver disturbances, in order to identify any change in liver enzymes during therapy. Patients admitted in an internal medicine department were treated with a complex therapeutic scheme, including antivirals. Beside the follow up for the evolution of the disease, we also monitored the potential occurrence of side effects, especially liver damage. Our results showed that none of the three antivirals that we used produced severe or significant liver disturbances. Our conclusion may be useful in guiding clinical practice, adding more information for the medical community.

Abstract: (1) Background: The antiviral treatment for COVID-19 disease started to be largely used in 2020 and has been found to be efficient, although it is not specific for SARS-CoV-2 virus. There were some concerns that it may produce liver damage or other side effects. (2) Methods: The aim of this study was to observe if antiviral therapy is affecting liver parameters or producing other side-effects in patients hospitalized for COVID-19 disease. The study included a group of patients hospitalized in the internal medicine department of Oradea Municipal Clinical Hospital, Romania, between August 2020-June 2021, diagnosed with SARS-CoV-2 viral infection by RT-PCR method or rapid antigen test. During hospitalization, patients were treated with a Lopinavir/Ritonavir (Kaletra) combination, or with Favipiravir or Remdesivir. In addition to monitoring the evolution of the disease (clinical and biochemical), also hepatic parameters were analyzed at admission, during hospitalization, and at discharge. (3) Results: In the group of studied patients, the mean value of aspartat aminotrensferase did not increase above normal at discharge, alanin aminotransferase increased, but below twice the normal values, and cholestasis registered a statistically insignificant slight increase. (4) Conclusions: In our study, we found that all three antivirals were generally well tolerated and their use did not alter liver function in a significant manner.

Keywords: coronavirus; antivirals; hepatic parameters; COVID-19

\section{Introduction}

Infection with the new coronavirus is currently the most important topic worldwide [1-4]. The emergence of COVID-19 disease implies collaboration and an interdisciplinary effort for its understanding and characterization [3].

In practice, the study of patients with COVID-19 evidenced a different evolution from individual to individual, with only a series of common manifestations $[5,6]$.

The mechanism of action for coronavirus, as well as its appropriate treatment, is still being studied [7]. Recent studies indicate that mortality with COVID-19 is also associated with increased cardiovascular risk, coagulopathy, and disseminated intravascular coagulation [8-10]. 
The treatment plan for viral or mixed (viral and bacterial) pneumonia includes antiviral, anticoagulant, anti-inflammatory (Dexamethasone), and antibiotic drugs [11-13]. In the clinical forms in which cytokine storm occurs, the treatment plan is supplemented with immunomodulators (Tocilizumab or Anakinra) [14-16].

The 2019 coronavirus disease pandemic (COVID-19), due to the new severe acute respiratory syndrome (SARS-CoV-2), has led worldwide to a sharp increase in hospitalization of patients with pneumonia and multiorgan diseases [16-19].

The antiviral treatment started to be largely used in 2020, although it is not specific for SARS-CoV-2 virus. From a chronological point of view, at the beginning a combination of two antiretrovirals was used Lopinavir/Ritonavir, then Remdesivir and Favipiravir.

However, there were some concerns about potential liver damage or other side effects.

Especially the combination of Lopinavir/Ritonavir was strongly criticized for not being effective against COVID-19 disease and having side effects, one of them being the alteration of hepatic function. In our department of internal medicine we had many patients who refused this therapy and signed in their medical file. Also there were some reserves for Favipiravir and Remdesivir, as they were newly introduced drugs, with not too much previous experience in coronavirus disease.

The aim of the present study was to evaluate the hepatic function, hepatocytolysis, and cholestasis syndrome, and full blood count with neutrophils and platelets counts during treatment with antiviral medication, Ritonavir/Lopinavir (Kaletra), Favipiravir, and Remdesivir, from the beginning of hospitalization, during the treatment, and at discharge.

\section{Materials and Methods}

The research was focused on 272 patients diagnosed with SARS-CoV-2 viral infection, treated in the Internal Medicine Clinical Department of the "Gavril Curteanu" Municipal Clinical Hospital of Oradea, Romania, between 1 August 2020-7 June 2021 (date of discharge of the last COVID-19 patient from the Internal medicine department) diagnosed with SARS-CoV-2 viral infection by the RT-PCR method and subsequently, when it became available, by the rapid antigen test.

Among the study group, 36 patients were treated with Lopinavir/Ritonavir (Kaletra) (L/R), 85 patients with Remdesivir, and 151 patients with Favipiravir. L/R treatment was subsequently withdrawn from the protocol of the Ministry of Health; there were also patients who refused to receive this treatment combination. Patients with significant pre-existing liver damage (chronic hepatitis with hepatocytolysis or severe cholestasis, liver cirrhosis, and liver metastases) were excluded from the study. The results of the computer tomography (CT) scan of the abdomen were also evaluated to rule out causes of liver damage.

In order to establish the disease' severity, patients were evaluated from a clinical point of view and also with biochemical analysis and thoracic, abdominal, and cranial CT (as needed). From the clinical point of view, mild forms were with no oxygen requirements, while severe forms required high flow oxygen support.

From the paraclinical point of view, to determine the severity of the disease, whether its mild, moderate, or severe, and also if it is viral or mixed COVID-19 pneumonia (viral and bacterial), the most important criteria was the degree of lung involvement described at computer tomography and the value of biochemical parameters characteristic for this coronavirus $(C$ reactive protein, $E S R$ = erythrocite sedimentation rate, lactate dehydrogenase, creatinkinase, limphocytes, plateletes, and D-dimers). Also, damage to other organs and systems caused by coronavirus and the presence of co-morbidities were used in order to classify the severity of the disease.

Subsequently, drug treatment was initiated, in accordance with the protocols of the Ministry of Health in force at that time and was adapted to every clinical forms of the disease.

The treatment was based on administration of antiviral (Lopinavir/Ritonavir-Kaletra, Remdesivir-Veklury, Favipiravir-Fluguard), anticoagulant, steroidal anti-inflammatory, 
antibiotic, as well as immunomodulators drugs, in the case of clinical and biochemical aggravation in the 8-12 days of the disease (cytokine storm), with favorable clinical evolution in most cases.

In the Ministry of Health protocol, the potential side effects of antiviral drugs are the following_-for the combination Lopinavir/Ritonavir: hepatocytolysis syndrome/cholestasis, leukopenia, nausea, and vomiting; for Remdesivir: hepatocytolysis syndrome/cholestasis, thrombocytopenia, thrombocytopenia; and for Favipiravir: hyperuricemia, diarrhea, hepatocytolysis/cholestasis syndrome, and thrombocytopenia.

The monitored biochemical parameters were the following:

- for Favipiravir, hepatocytolysis and cholestasis syndrome (GOT, GPT, GGT, ALP, and total as well as uric acid value)

- for Remdesivir, hepatocytolysis and cholestasis syndrome (GOT, GPT, GGT, ALP, and total as well as the value of neutrophils and platelets)

- for Lopinavir/Ritonavir, hepatocytolysis syndrome, cholestasis, as well as the value of neutrophils and platelets.

The value of these parameters was determined initially (at hospitalization), during treatment, and on the day before discharge.

The results of the CT scan of the abdomen were also evaluated in order to rule out causes of pre-existing liver damage (chronic viral hepatitis, liver cirrhosis, liver metastases, etc.). All subjects gave their informed consent for inclusion before they participated in the study, conducted in accordance with the Declaration of Helsinki.

Data processing was performed using the SPSS 20 program. Frequency ranges, average parameter values, and standard deviations were calculated. Tests of statistical significance by the $\chi 2$ method were used, and ANOVA (Brown-Forsythe) was used to compare the means. The level of statistical significance was 0.05 .

\section{Results}

\subsection{Characteristics of the Population (Sex, Age, and Environment)}

In our study group, over $50 \%$ were women $(51.10 \%)$, the ratio of women/men was 1 : 1 , the age was between $26-88$ years, the average age was 60.18 years, and the patients came mainly from the urban environment $(55.88 \%)$; (Table 1$)$ the urban/rural ratio was 1.3:1.

Table 1. Characteristics of the population.

\begin{tabular}{ccccc}
\hline & No. & \% & Min/Max & MD \pm DS \\
\hline Sex (F/M) & $139 / 133$ & $51.10 / 48.90$ & & \\
\hline Age (years) & & & $26-88$ & $60.18 \pm 13.06$ \\
\hline Environment (U/R) & $152 / 120$ & $55.88 / 44.12$ & & \\
\hline
\end{tabular}

In the Lopinavir/Ritonavir (Kaletra) (L/R) batch, men predominated (58.33\%), the percent being insignificantly higher than in the Remdesivir and Favipiravir groups (48.24\%, $p=0.312$, respectively $47.02 \%, p=0.224$ ).

\subsection{The Severity of the Disease}

The severe form of the disease was found in $82.35 \%$ of patients from the Remdesivir batch, significantly higher than in the L/R and Favipiravir groups $(41.67 \%$ and $54.97 \%$, respectively, $p<0.001$ ), (Table 2, Figure 1). 
Table 2. Distribution of cases according to the severity of the disease.

\begin{tabular}{ccccccc}
\hline Severity of the Disease & \multicolumn{2}{c}{ Lopinavir/Ritonavir (Kaletra) } & \multicolumn{2}{c}{ Remdesivir } & \multicolumn{2}{c}{ Favipiravir } \\
\hline Mild & 3 & $8.33 \%$ & 2 & $2.35 \%$ & 18 & $11.92 \%$ \\
\hline Moderate & 18 & 50.00 & 13 & 15.29 & 50 & 33.11 \\
\hline Severe & 15 & 41.67 & 70 & 82.35 & 83 & 54.97 \\
\hline
\end{tabular}

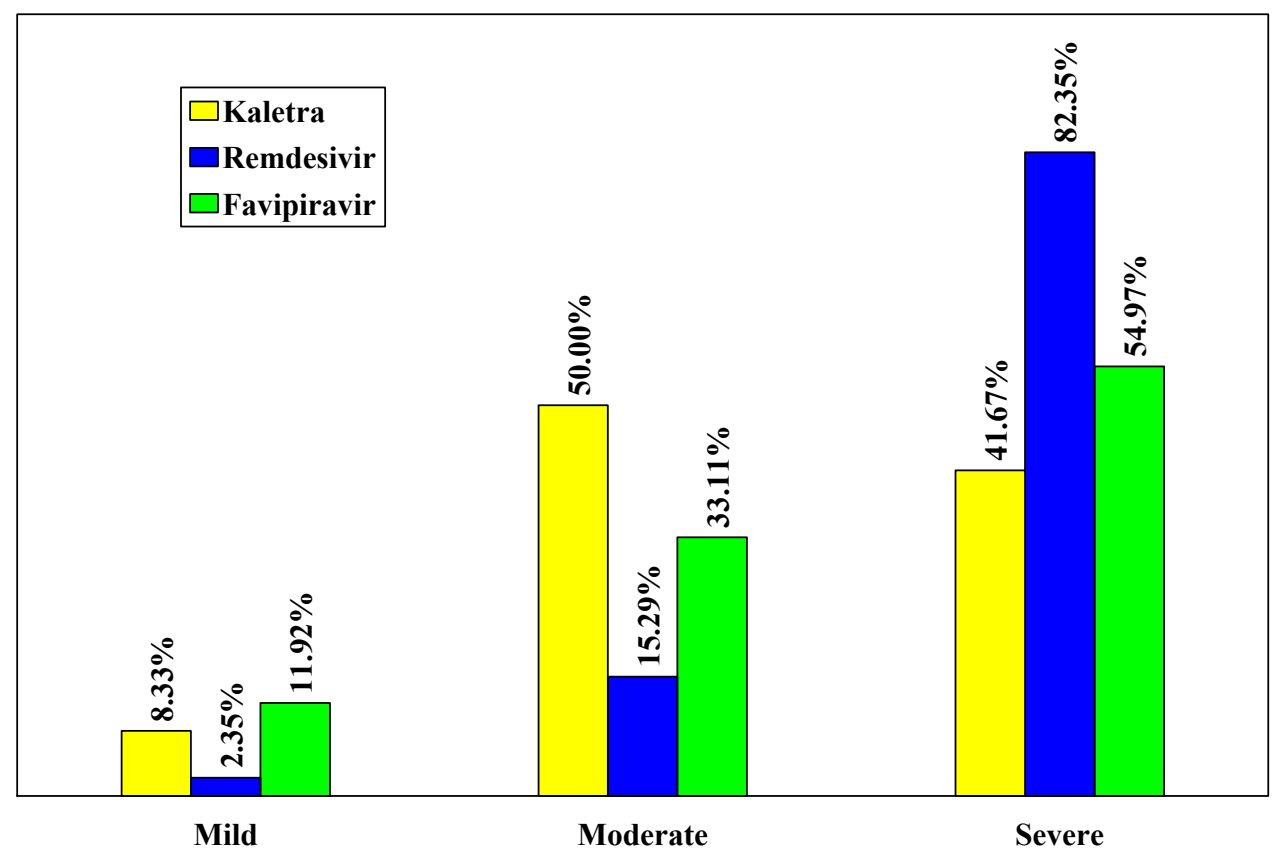

Figure 1. Distribution of cases according to the severity of the disease.

\subsection{Evolution of Hepatic Function Parameters}

The normal laboratory GOT values are between 0 and $50 \mathrm{U} / \mathrm{L}$.

Slightly increased values at hospitalization were interpreted as occurring in the context of the disease, the SARS-CoV-2 virus also causing liver damage.

In the L/R and Favipiravir groups, the GOT values had a decreasing trend, and in the case of Remdesivir, they had a convex evolution (Table 3).

Table 3. GOT evolution.

\begin{tabular}{ccccccc}
\hline GOT & at Hospitalization & after Administration & $\mathbf{P}^{\mathbf{1}-\mathbf{2}}$ & at Discharge & $\mathbf{P}^{\mathbf{1}-\mathbf{3}}$ & $\mathbf{P}^{\mathbf{2}-\mathbf{3}}$ \\
\hline Lopinavir/Ritonavir (Kaletra) & $56.58 \pm 34.01$ & $45.65 \pm 27.30$ & 0.142 & $44.26 \pm 29.99$ & 0.112 & 0.843 \\
\hline Remdesivir & $51.11 \pm 31.65$ & $52.12 \pm 31.57$ & 0.834 & $45.12 \pm 33.27$ & 0.231 & 0.161 \\
\hline Favipiravir & $51.72 \pm 28.36$ & $45.48 \pm 30.11$ & 0.066 & $40.35 \pm 23.41$ & $<0.001$ & 0.102 \\
\hline $\mathrm{p}^{\mathrm{K}-\mathrm{R}}$ & 0.412 & 0.268 & & 0.892 & \\
\hline $\mathrm{p}^{\mathrm{K}-\mathrm{F}}$ & 0.432 & 0.975 & & 0.480 \\
\hline $\mathrm{p}^{\mathrm{R}-\mathrm{F}}$ & 0.882 & 0.117 & & 0.246 \\
\hline
\end{tabular}

Thus, compared to the values at hospitalization, in the $\mathrm{L} / \mathrm{R}$ and Favipiravir groups, the GOT values decreased insignificantly after administration (from $56.58 \mathrm{U} / \mathrm{L}$ to $45.65 \mathrm{U} / \mathrm{L}$, $p=0.142$ and from $51.72 \mathrm{U} / \mathrm{L}$ to $45.48 \mathrm{U} / \mathrm{L}, p=0.066$, respectively), further decreasing, so that, at discharge, the decrease in the case of Kaletra batch was insignificant (from $56.58 \mathrm{U} / \mathrm{L}$ to $44.26 \mathrm{U} / \mathrm{L}, p=0.112$ ), whereas the decrease in the Favipiravir batch was significant (from $51.72 \mathrm{U} / \mathrm{L}$ to $40.35 \mathrm{U} / \mathrm{L}, p<0.001$ ). 
In the Remdesivir batch, GOT values increased insignificantly after administration (from $51.11 \mathrm{U} / \mathrm{L}$ to $52.12 \mathrm{U} / \mathrm{L}, p=0.834$ ) and decreased insignificantly at discharge from $51.11 \mathrm{U} / \mathrm{L}$ to $45.12 \mathrm{U} / \mathrm{L}, p=0.231$ ).

The comparison of the three groups, at hospitalization, during administration, and at discharge shows no significant differences in GOT values $(p>0.05)$, while the use of each of the three drugs did not lead to increased GOT (Figure 2).

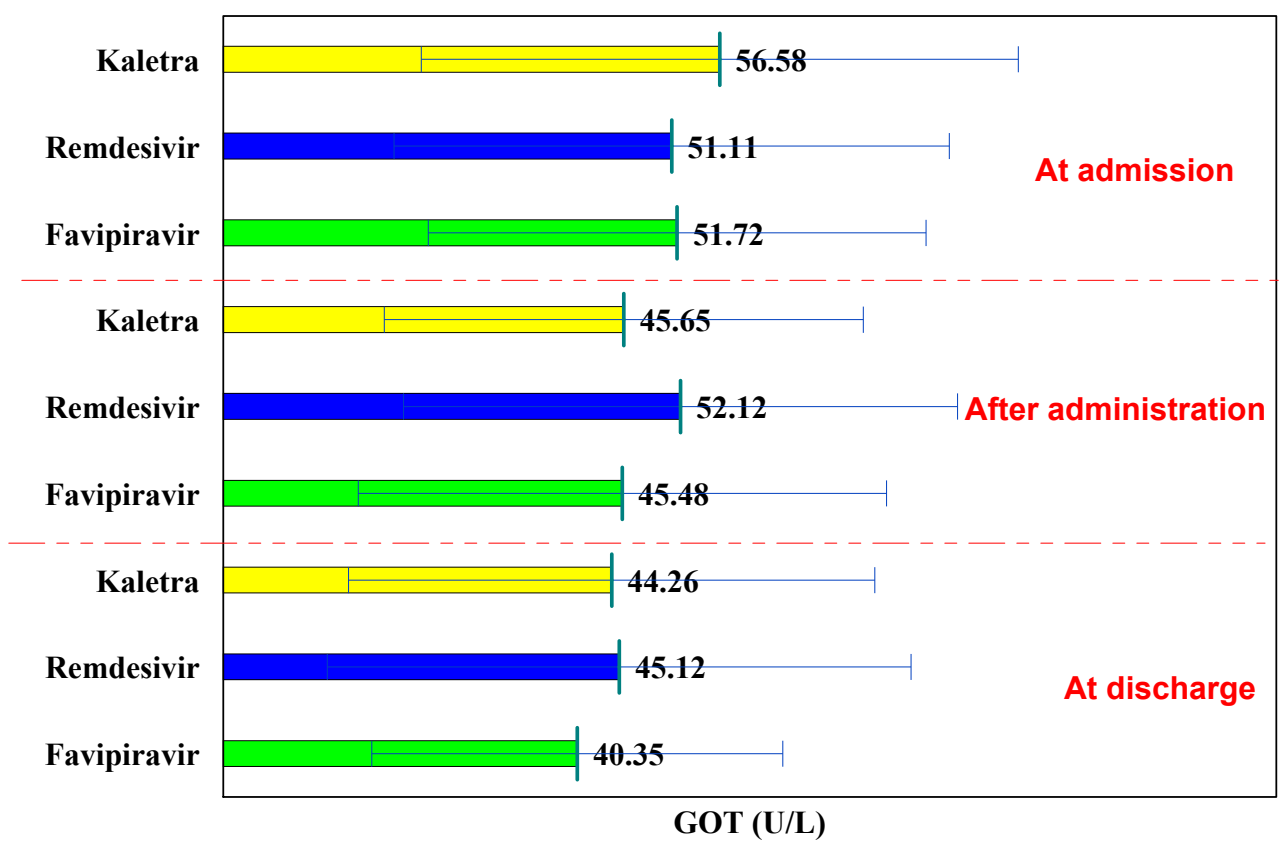

Figure 2. GOT evolution.

The normal laboratory GPT values are between 0 and $50 \mathrm{U} / \mathrm{L}$.

In all three groups, GPT values followed an increasing curve at hospitalization, after administration, and at discharge. In the L/R batch, the GPT values at hospitalization were $47.67 \mathrm{U} / \mathrm{L}$, after administration of $52.85 \mathrm{U} / \mathrm{L}(p=0.477)$, and at discharge $60.94 \mathrm{U} / \mathrm{L}$ $(p=0.114)$, (Table 4$)$.

Table 4. GPT evolution.

\begin{tabular}{|c|c|c|c|c|c|c|}
\hline GPT & at Hospitalization & after Administration & $\mathbf{P}^{1-2}$ & at Discharge & $\mathbf{P}^{1-3}$ & $\mathbf{P}^{2-3}$ \\
\hline Lopinavir/Ritonavir (Kaletra) & $47.67 \pm 28.75$ & $52.85 \pm 31.72$ & 0.477 & $60.94 \pm 39.32$ & 0.114 & 0.354 \\
\hline Remdesivir & $45.47 \pm 34.49$ & $57.47 \pm 41.36$ & 0.042 & $66.53 \pm 54.74$ & 0.003 & 0.225 \\
\hline Favipiravir & $48.99 \pm 34.33$ & $59.39 \pm 44.40$ & 0.025 & $59.67 \pm 44.64$ & 0.022 & 0.957 \\
\hline $\mathrm{p}^{\mathrm{K}-\mathrm{R}}$ & 0.719 & 0.514 & & 0.535 & & \\
\hline $\mathrm{p}^{\mathrm{K}-\mathrm{F}}$ & 0.812 & 0.322 & & 0.869 & & \\
\hline $\mathrm{p}^{\mathrm{R}-\mathrm{F}}$ & 0.453 & 0.740 & & 0.328 & & \\
\hline
\end{tabular}

Comparatively to the baseline in the Remdesivir and Favipiravir batch, GPT increased significantly after administration (from $45.47 \mathrm{U} / \mathrm{L}$ to $57.47 \mathrm{U} / \mathrm{L}, p=0.042$, and from $48.9 \mathrm{U} / \mathrm{L}$ to $59.39 \mathrm{U} / \mathrm{L}, p=0.025$, respectively), at discharge the GPT values being significantly higher (from $45.47 \mathrm{U} / \mathrm{L}$ to $66.53 \mathrm{U} / \mathrm{L}, p=0.003$ and from $48.99 \mathrm{U} / \mathrm{L}$ to $59.67 \mathrm{U} / \mathrm{L}$, $p=0.022$, respectively).

Comparing the three study groups, at hospitalization, after administration, and at discharge, no significant differences were observed in terms of GPT values $(p>0.05)$. In each of the administered drugs, GPT at discharge was higher than normal, but below 
$2 x$ the normal value. At discharge, hepatoprotective treatment was prescribed to these patients (Figure 3).

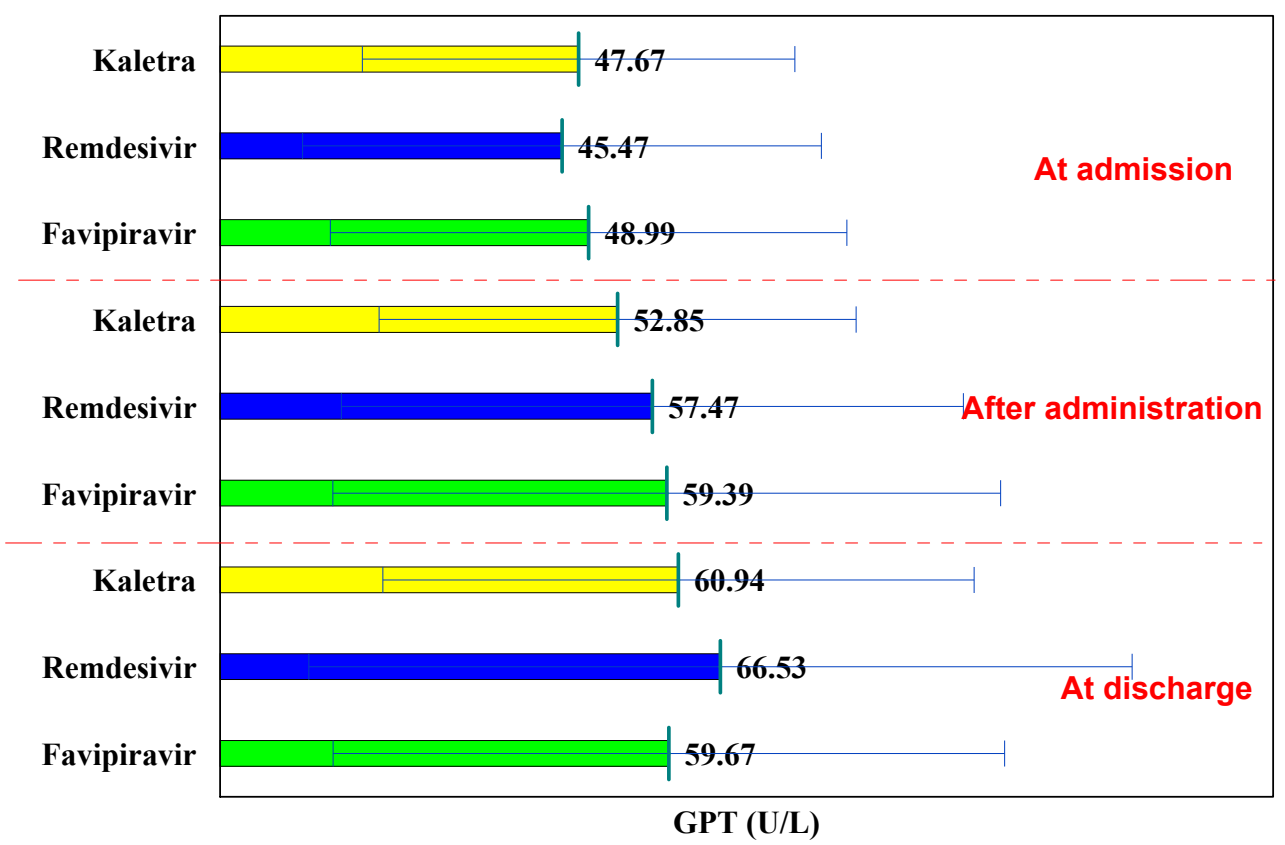

Figure 3. GPT evolution.

The normal laboratory GGT values are between 0 and $50 \mathrm{U} / \mathrm{L}$. GGT values were recorded only in Remdesivir and Favipiravir groups, at hospitalization and at discharge. In both groups, the GGT increased insignificantly (from $59.14 \mathrm{U} / \mathrm{L}$ to $62.59 \mathrm{U} / \mathrm{L}$ in the Remdesivir group, $p=0.633$ and in the case of Favipiravir from $81.45 \mathrm{U} / \mathrm{L}$ to $97.01 \mathrm{U} / \mathrm{L}$, $p=0.437$, respectively), (Table 5).

Table 5. GGT evolution.

\begin{tabular}{cccc}
\hline GGT & at Hospitalization & at Discharge & P1-3 $^{\mathbf{3}}$ \\
\hline Remdesivir & $59.14 \pm 40.27$ & $62.59 \pm 52.77$ & 0.633 \\
\hline Favipiravir & $81.45 \pm 51.56$ & $97.01 \pm 69.41$ & 0.437 \\
\hline $\mathrm{p}^{\mathrm{R}-\mathrm{F}}$ & 0.055 & 0.067 & \\
\hline
\end{tabular}

At hospitalization, GGT values were slightly higher in the Favipiravir batch (81.45 U/L versus 59.14 U/L, $p=0.055)$. Both Remdesivir and Favipiravir treatments cause a slight increase in GGT (cholestasis), (Figure 4).

The normal laboratory neutrophils values are between 1800 and $7500 / \mathrm{mm}^{3}$. In all three batches, they followed an increasing curve at hospitalization, after administration, and at discharge.

In the $\mathrm{L} / \mathrm{R}$ batch, the values of neutrophils at hospitalization were $4.43 \times 10^{3} / \mathrm{dL}$; after administration, they increased significantly to $8.22 \times 10^{3} / \mathrm{dL}(p<0.001)$, and at discharge the values were $8.62 \times 10^{3} / \mathrm{dL}(p<0.001)$ (Table 6$)$. 


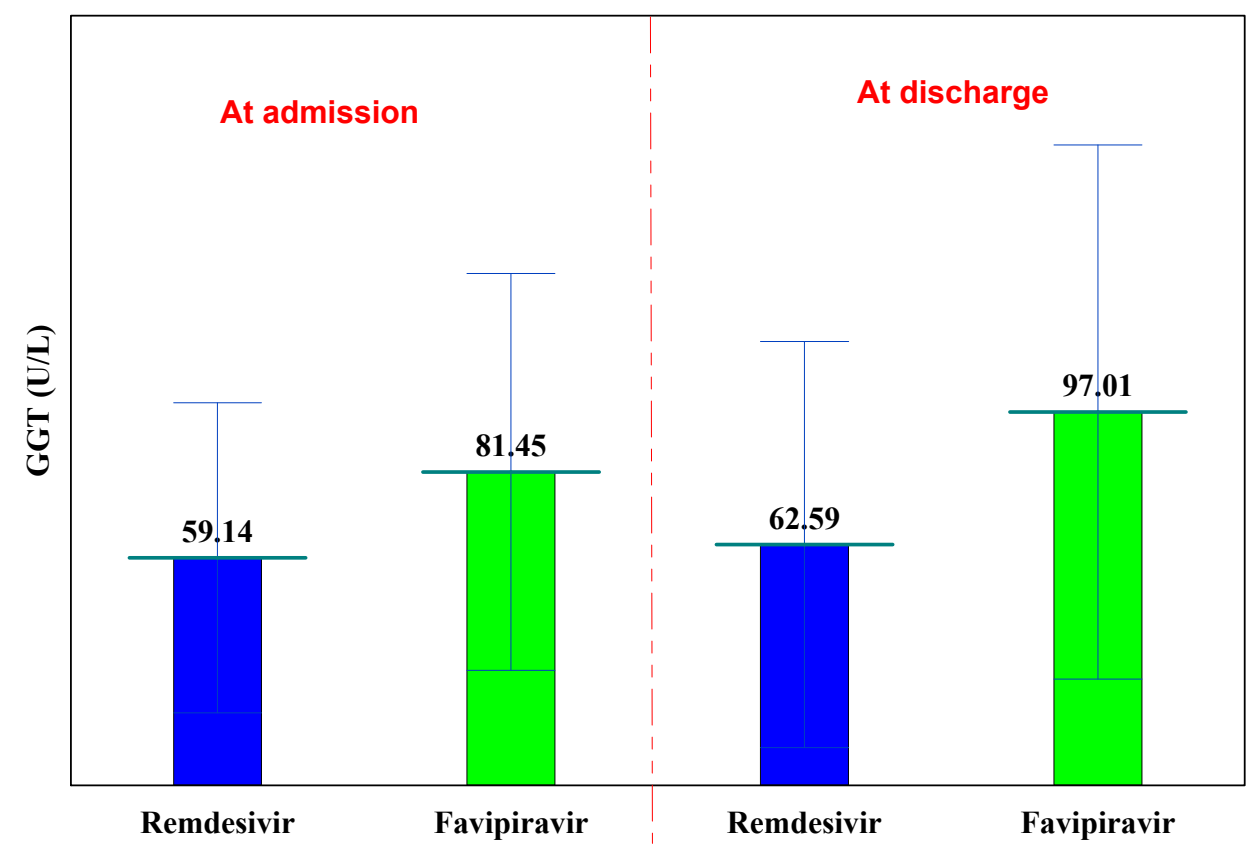

Figure 4. GGT evolution.

Table 6. Evolution of neutrophils.

\begin{tabular}{ccccccc}
\hline Neutrophils & at Hospitalization & after Administration & $\mathbf{P}^{\mathbf{1}-\mathbf{2}}$ & at Discharge & $\mathbf{P}^{\mathbf{1}-\mathbf{3}}$ & $\mathbf{P}^{\mathbf{2}-\mathbf{3}}$ \\
\hline Lopinavir/Ritonavir (Kaletra) & $4.43 \pm 2.52$ & $8.22 \pm 4.67$ & $<0.001$ & $8.62 \pm 5.15$ & $<0.001$ & 0.740 \\
\hline Remdesivir & $6.74 \pm 5.47$ & $8.98 \pm 5.75$ & 0.010 & $12.82 \pm 11.62$ & $<0.001$ & 0.007 \\
\hline Favipiravir & $5.55 \pm 3.62$ & $7.90 \pm 5.51$ & $<0.001$ & $8.10 \pm 4.78$ & $<0.001$ & 0.737 \\
\hline $\mathrm{p}^{\mathrm{K}-\mathrm{R}}$ & 0.002 & 0.460 & & 0.007 & \\
\hline $\mathrm{p}^{\mathrm{K}-\mathrm{F}}$ & 0.034 & 0.727 & & 0.595 & \\
\hline $\mathrm{p}^{\mathrm{R}-\mathrm{F}}$ & 0.077 & 0.165 & & 0.001 & \\
\hline
\end{tabular}

In the Remdesivir batch, the values of neutrophils at hospitalization were $6.74 \times 10^{3} / \mathrm{dL}$, after administration they increased significantly to $8.98 \times 10^{3} / \mathrm{dL}(p=0.010)$, and at discharge the values were $12.82 \times 10^{3} / \mathrm{dL}(p<0.001)$.

In the Favipiravir group, the values of neutrophils at hospitalization were $5.55 \times 10^{3} / \mathrm{dL}$, after administration they increased significantly to $7.90 \times 10^{3} / \mathrm{dL}(p<0.001)$, and at discharge the values were $8.10 \times 10^{3} / \mathrm{dL}<0.001$ ).

Comparison of the three groups shows that, at hospitalization, the values of neutrophils were $4.43 \times 10^{3} / \mathrm{dL}$, significantly lower than in the Remdesivir and Favipiravir batch $\left(6.74 \times 10^{3} / \mathrm{dL}, p=0.002\right.$, respectively $\left.5.55 \times 10^{3} / \mathrm{dL}, p=0.034\right)$.

After administration, there were no significant differences among the three groups, while at discharge, the highest neutrophil values were recorded in the Remdesivir batch $\left(12.82 \times 10^{3} / \mathrm{dL}\right)$, significantly higher than in the Lopinavir/Ritonavir and Favipiravir batch $\left(8.62 \times 10^{3} / \mathrm{dL}, p=0.007\right.$, respectively $\left.8.10 \times 10^{3} / \mathrm{dL}, p=0.001\right)$. The patients analyzed in this study did not develop leukopenia using these three antiviral drugs (Figure 5). 


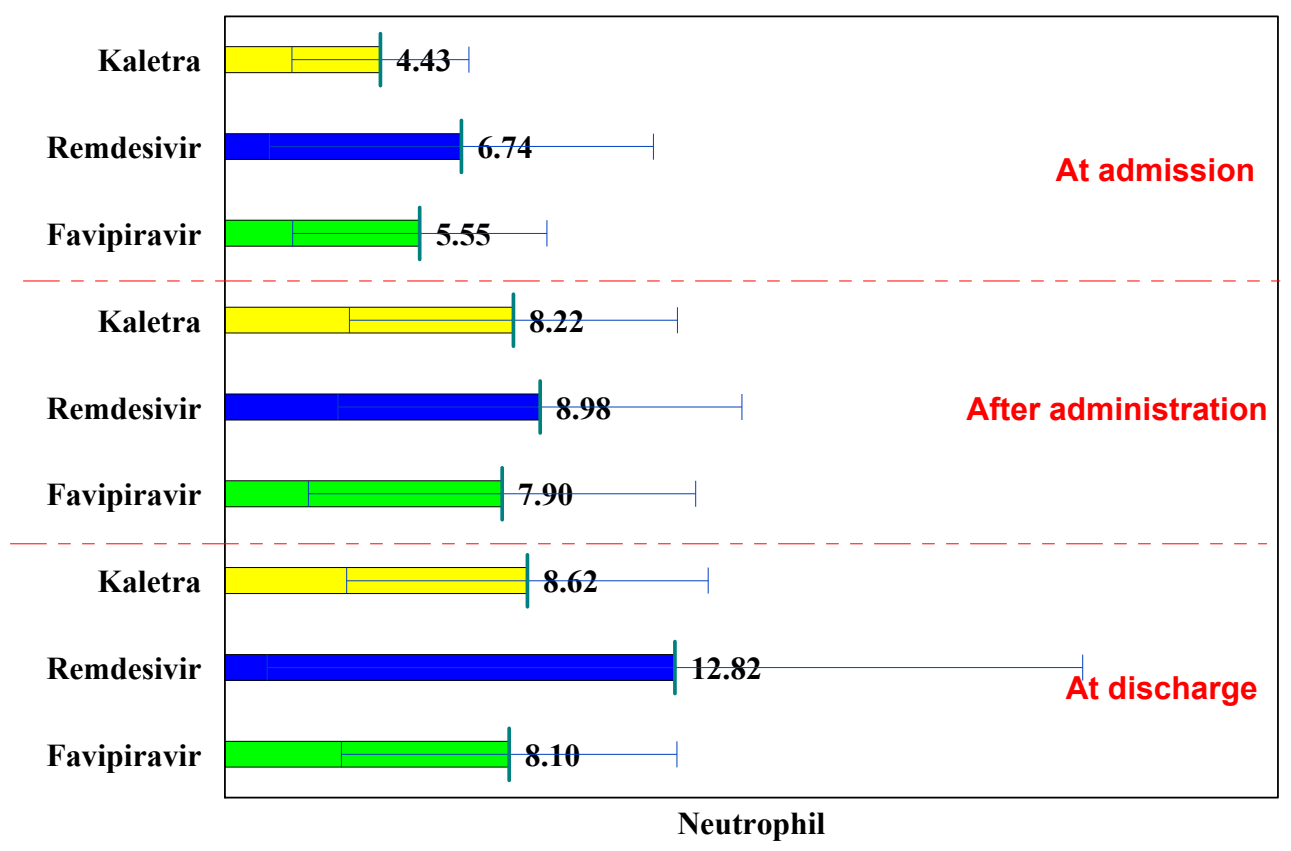

Figure 5. Neutrophils evolution.

The normal laboratory platelets values are between $150,000-400,000 / \mathrm{mm}^{3}$.

In the $\mathrm{L} / \mathrm{R}$ batch, platelet values had a concave evolution, increasing after administration, and decreasing at discharge, while in the Remdesivir and Favipiravir batches, the trend was increasing. These variations did not exceed normal values.

Compared to the initial evaluation, in all three batches, the values increased significantly after administration (from $208.20 \times 10^{3} \mu \mathrm{L}$ to $316.59 \times 10^{3} \mu \mathrm{L}, p<0.001$; from $237.69 \times 10^{3} \mu \mathrm{L}$ to $294.12 \times 10^{3} \mu \mathrm{L}, p=0.001$; and from $231.83 \times 10^{3} \mu \mathrm{L}$ to $283.74 \times 10^{3} \mu \mathrm{L}$, $p<0.001$ ) and remained significantly higher at discharge from $208.20 \times 10^{3} \mu \mathrm{L}$ to $286.59 \times 10^{3} \mu \mathrm{L}$, $p=0.004$; from $237.69 \times 10^{3} \mu \mathrm{L}$ to $296.53 \times 10^{3} \mu \mathrm{L}, p<0.001$; and from $231.83 \times 10^{3} \mu \mathrm{L}$ to $\left.297.99 \times 10^{3} \mu \mathrm{L}, p<0.001\right)$, (Table 7).

Table 7. Platelets evolution.

\begin{tabular}{ccccccc}
\hline Platelets & at Hospitalization & after Administration & $\mathbf{P}^{\mathbf{1}-\mathbf{2}}$ & at Discharge & $\mathbf{P}^{\mathbf{1}-\mathbf{3}}$ & $\mathbf{P}^{\mathbf{2}-\mathbf{3}}$ \\
\hline Lopinavir/Ritonavir (Kaletra) & $208.20 \pm 82.90$ & $316.59 \pm 104.85$ & $<0.001$ & $286.59 \pm 128.22$ & 0.004 & 0.295 \\
\hline Remdesivir & $237.69 \pm 104.47$ & $294.12 \pm 111.79$ & 0.001 & $296.53 \pm 109.53$ & $<0.001$ & 0.887 \\
\hline Favipiravir & $231.83 \pm 97.34$ & $283.74 \pm 123.27$ & $<0.001$ & $297.99 \pm 119.79$ & $<0.001$ & 0.316 \\
\hline $\mathrm{p}^{\mathrm{K}-\mathrm{R}}$ & 0.106 & 0.304 & & 0.692 & \\
\hline $\mathrm{p}^{\mathrm{K}-\mathrm{F}}$ & 0.148 & 0.117 & & 0.639 & \\
\hline $\mathrm{p}^{\mathrm{R}-\mathrm{F}}$ & 0.673 & 0.513 & & 0.925 & \\
\hline
\end{tabular}

At hospitalization, after administration and at discharge, no significant differences were observed in all three groups in terms of platelet values $(p>0.05)$. The use of the three antiviral drugs did not cause thrombocytopenia (Figure 6). 


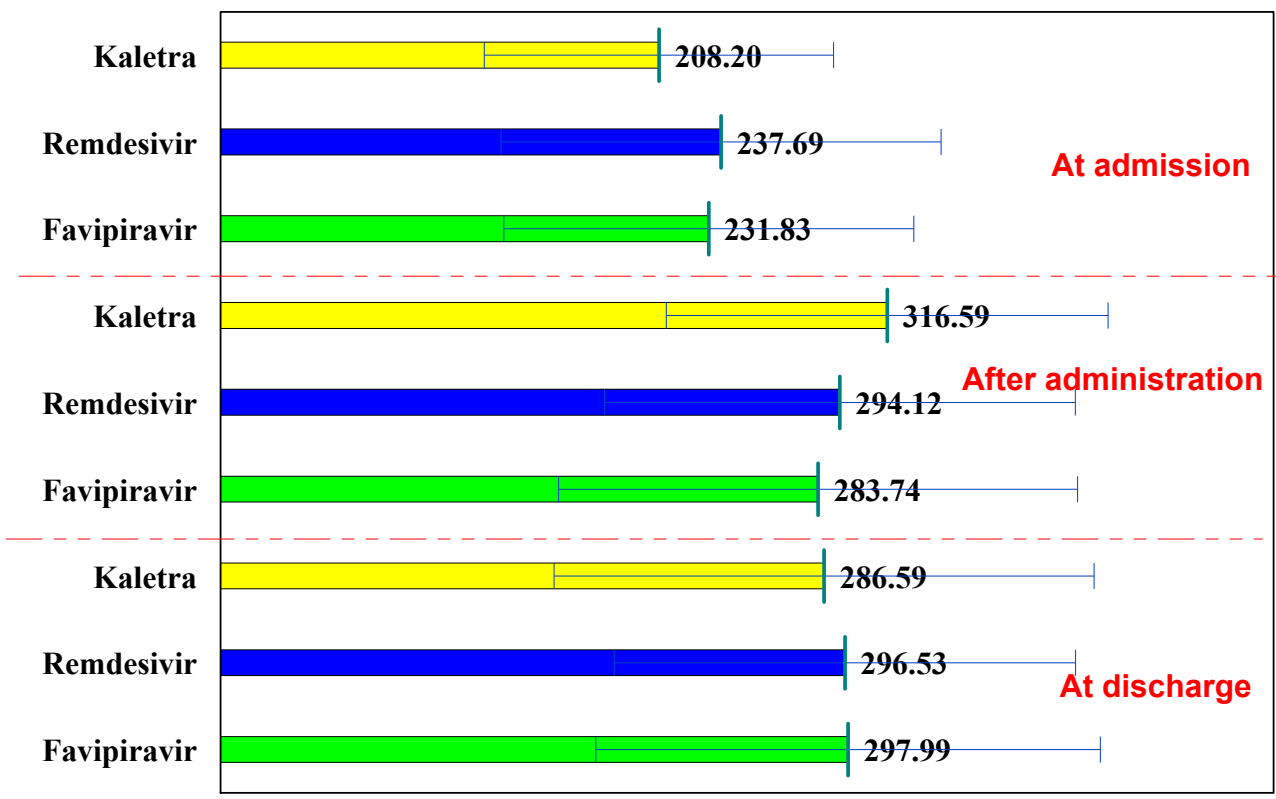

Platelets

Figure 6. Platelet evolution.

CT images of the liver revealed changes only in the Remdesivir and Favipiravir groups $(10.58 \%$ vs $5.96 \%, p=0.199)$ (Table 8 , Figure 7 ).

Table 8. Distribution of cases according to CT image of the liver.

\begin{tabular}{ccccccc}
\hline & Lopinavir/Ritonavir (Kaletra) & \multicolumn{2}{c}{ Remdesivir } & \multicolumn{2}{c}{ Favipiravir } \\
\hline Normal & 36 & 100.00 & 76 & 89.41 & 142 & 94.04 \\
\hline Irregular contour & 0 & 0.00 & 0 & 0.00 & 2 & 1.32 \\
\hline Increased dimensions & 0 & 0.00 & 2 & 2.35 & 2 & 1.32 \\
\hline Liver nodules & 0 & 0.00 & 1 & 1.18 & 1 & 0.66 \\
\hline Hepatic steatosis & 0 & 0.00 & 6 & 7.06 & 4 & 2.65 \\
\hline
\end{tabular}

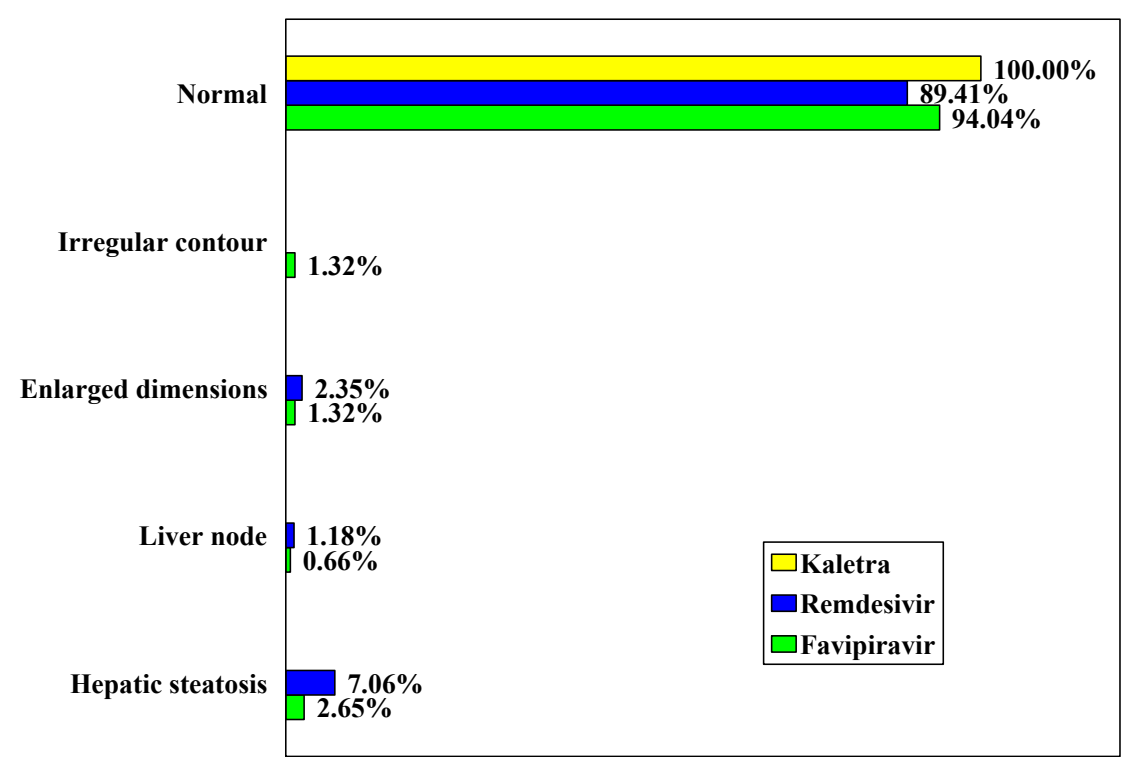

Figure 7. Distribution of cases according to CT image of the liver. 


\section{Discussion}

Liver plays a major role in many diseases and proves to be important also in COVID-19. There are several theories proposed for liver damage in COVID-19, such as direct effect of the virus on hepatocytes or biliary epithelium via Angiotensin-converting enzyme (ACE2) receptors expression, liver injury related to increased immune response (Cytokine storm) and immune-mediated damage, drug toxicity (Acetaminophen, antivirals or Hydroxychloroquine), and liver failure occurring in patients having multiorgan dysfunction [20-24].

In our study we excluded patients with acute liver injury and elevated liver enzymes at admission, these findings being associated with increased severity and poor outcome. The drugs used in treating COVID-19 disease were initially intended for other diseases (viruses). Various drugs are being used as repurposed drugs, as there is no specific drug or effective treatment strategy against COVID-19. Multiple challenges associated with repurposed drugs have been identified, including dose adjustments, route of administration, and acute/chronic toxicity. The relationship between the drugs used for COVID-19 treatment and liver disturbance remains controversial. It is essential to evaluate the potential liver damage caused by various drugs in order to help guide clinical practice [25-29].

In our study, antiviral treatment was offered to an approximately equal number of women and men (139 women and 133 men), with a mean age of 59.95 years.

The low number of patients has several explanations; for example, there was a strong opinion in the population that the combination Lopinavir/Ritonavir is not effective against the coronavirus SARS-CoV-2, and some patients refused the administration of this drug and signed in their consent. Also, there were some reserves against Favipiravir and Remdesivir, because they were newly introduced drugs; another serious problem was that patients arrived at the hospital after 10 or more days of treatment at home, and antiviral therapy was not useful anymore. Patients with high levels of aminotransferases were excluded from the study.

Chronologically, Lopinavir/Ritonavir (Kaletra), Remdesivir, and Favipiravir treatments were administrated to patients with COVID-19 pneumonia. The treatment was performed according to the recommendations of the Ministry of Health protocols in force at that time. The Lopinavir-Ritonavir treatment was withdrawn from the protocol, but the other two drugs remained as a recommendation. Remdesivir was used for the treatment of severe forms of the disease, and Favipiravir for mild and moderate forms.

Due to warnings that antiviral therapy may lead to impaired liver function, increased attention has been provided to hepatic parameters during the treatment including the three antiviral drugs, therefore, parameters indicating hepatocytolysis and cholestasis have been monitored more frequently.

In a randomized controlled study on Lopinavir/Ritonavir-treated adult patients hospitalized with mild/moderate disease, only one patient developed elevation over 2.5-fold above the normal limit [30].

In our study, GOT (aspartat aminotransferase) did not increase and GPT (alanin aminotransferase) increased from a median value of $47.67 \mathrm{U} / \mathrm{L}$ to $60.94 \mathrm{U} / \mathrm{L}$. Also, this combination does not influence the values of neutrophils and platelets.

The association of Remdesivir with liver injury remains uncertain and is essential to evaluate the safety of this drug. One randomized multicenter trial with 237 patients [31] found similar aminotransferases levels between Remdesivir and placebo group. In our study, GOT did not increase, but the value of GPT increased from a median value of $45.4 \mathrm{U} / \mathrm{L}$ to $66.5 \mathrm{U} / \mathrm{L}$. We also observed a slight elevation of cholestasis-gammaglutamil transpeptidase increased from 59.1 to $62.5 \mathrm{U} / \mathrm{L}$ and had no negative effect on the number of neutrophils and plateletes.

In a recent article [32], it was stated that it is important to evaluate the potential liver damage caused by various drugs in order to help guide clinical practice. In this review, these treatments were associated with minimal liver function abnormalities, but it is very important to pay attention to multimedication. In fact, we found references about 
Lopinavir/Ritonavir and Remdesivir, but few references about Favipiravir. Also, we made a comparison between the three antivirals and the effect of each one on liver parameters.

In our study, Favipiravir did not alter the value of GOT; GPT registered a change from $48.9 \mathrm{U} / \mathrm{L}$ to $59.6 \mathrm{U} / \mathrm{L}$ and also cholestasis enzyme increased-from 81.4 to $97.0 \mathrm{U} / \mathrm{L}$. The levels of neutrophils and platelets were not affected.

\section{Conclusions}

From the viewpoint of the hepatic function damage (hepatocytolysis syndrome), the treatment with the three antiviral drugs did not lead to an increase in GOT values. Instead, the value of GPT increased after the use of each of the three drugs, but only slightly; no doubling of the values was recorded with any of the drugs. We observed that Remdesivir has the highest influence on the value of GPT, but not in a dangerous manner. In fact, no patient was withdrawn from the therapy.

Regarding the cholestasis syndrome, the GGT value increased slightly, but statistically insignificant, under the influence of treatments with Favipiravir and Remdesivir. Favipiravir caused a more pronounced cholestasis syndrome than Remdesivir.

The parameters related to the full blood count-the neutrophils and platelets, which could have been modified by the antiviral treatment-were not negatively influenced by the use of the three drugs, so no neutropenia or thrombocytopenia was observed.

The use of the three antiviral drugs did not cause major liver damage and, clinically, in most cases, the COVID-19 viral pneumonias had a favorable evolution.

These findings may be useful for the medical community, offering trust and adding more information about the fact that these antiviral drugs, although not specific, are not as dangerous as they seemed to be at the beginning of the pandemic.

Author Contributions: Conceptualization, F.M.; methodology, F.M., C.M. and A.H.; software, P.R. and L.S.; validation, C.S., L.S. and L.E.R.; Resources, D.M.F. and F.M.; writing L.S. and F.M.; supervision, L.S. and F.M. All authors have read and agreed to the published version of the manuscript. Authors contributed equally to this work.

Funding: This research received no external funding.

Institutional Review Board Statement: The study was conducted in accordance with the Declaration of Helsinki, and the protocol was approved by the Ethics Committee of Oradea University, nr.5/A, 21.09.2020.

Informed Consent Statement: Informed consent was obtained from all subjects involved in the study.

Data Availability Statement: Not applicable.

Conflicts of Interest: The authors declare no conflict of interest.

\section{Abbreviations}

RT-PCR (reverse transcription polymerase chain reaction), GOT (Aspartat aminotransferase), GPT (alanin aminotransferase) GGT (gammaglutamil-transpeptidase), ALP (alkaline phosphatase).

\section{References}

1. Zhu, N.; Zhang, D.; Wang, W.; Li, X.; Yang, B.; Song, J.; Zhao, X.; Huang, B.; Shi, W.; Lu, R.; et al. China Novel Coronavirus Investigating and Research Team. A novel coronavirus from patients with pneumonia in China, 2019. N. Engl. J. Med. 2020, 382, 727-733. [CrossRef] [PubMed]

2. Van de Veerdonk, F.L.; Netea, M.G.; van Deuren, M.; van der Meer, J.W.; de Mast, Q.; Brüggemann, R.J.; van der Hoeven, H. Kallikrein-kinin blockade in patients with COVID-19 to prevent acute respiratory distress syndrome. Elife 2020, 9, e57555. [CrossRef]

3. Leisman, D.E.; Ronner, L.; Pinotti, R.; Taylor, M.D.; Sinha, P.; Calfee, C.S.; Hirayama, A.V.; Mastroiani, F.; Turtle, C.J.; Harhay, M.O.; et al. Cytokine elevation in severe and critical COVID-19: A rapid systematic review, meta-analysis, and comparison with other inflammatory syndromes. Lancet Respir. Med. 2020, 8, 1233-1244. [CrossRef] 
4. Cummings, M.J.; Baldwin, M.R.; Abrams, D.; Jacobson, S.D.; Meyer, B.J.; Balough, E.M.; Aaron, J.G.; Claassen, J.; Rabbani, L.E.; Hastie, J.; et al. Epidemiology, clinical course, and outcomes of critically ill adults with COVID-19 in New York City: A prospective cohort study. Lancet 2020, 395, 1763-1770. [CrossRef]

5. Huang, C.; Wang, Y.; Li, X.; Ren, L.; Zhao, J.; Hu, Y.; Zhang, L.; Fan, G.; Xu, J.; Gu, X.; et al. Clinical features of patients infected with 2019 novel coronavirus in Wuhan, China. Lancet 2020, 395, 497-506. [CrossRef]

6. Li, H.; Liu, L.; Zhang, D.; Xu, J.; Dai, H.; Tang, N.; Su, X.; Cao, B. SARS-CoV-2 and viral sepsis: Observations and hypotheses. Lancet 2020, 395, 1517-1520. [CrossRef]

7. Zou, X.; Chen, K.; Zou, J.; Han, P.; Hao, J.; Han, Z. Single-cell RNA-seq data analysis on the receptor ACE2 expression reveals the potential risk of different human organs vulnerable to 2019-nCoV infection. Front. Med. 2020, 14, 185-192. [CrossRef]

8. Ruzzenetti, G.; Maloberti, A.; Giani, V.; Bolcati, M.; Leidi, F.; Monticelli, M.; Grasso, E.; Cartella, I.; Palazzini, M.; Garatti, L.; et al. Covid and Cardiovascular Diseases: Direct and Indirect Damages and Future Perspective. High Blood Press. Cardiovasc. Prev. 2021, 28, 439-445. [CrossRef]

9. Yao, X.H.; Li, T.Y.; He, Z.C.; Ping, Y.F.; Liu, H.W.; Yu, S.C.; Mou, H.M.; Wang, L.H.; Zhang, H.R.; Fu, W.J.; et al. A pathological report of three COVID-19 cases by minimally invasive autopsies. Zhonghua Bing Li Xue Za Zhi 2020, 49, 411-417.

10. Xu, Z.; Shi, L.; Wang, Y.; Zhang, J.; Huang, L.; Zhang, C.; Liu, S.; Zhao, P.; Liu, H.; Zhu, L.; et al. Pathological findings of COVID-19 associated with acute respiratory distress syndrome. Lancet Respir. Med. 2020, 8, 420-422. [CrossRef]

11. Li, H.; Chen, C.; Hu, F.; Wang, J.; Zhao, Q.; Gale, R.P.; Liang, Y. Impact of corticosteroid therapy on outcomes of persons with SARS-CoV-2, SARS-CoV, or MERS-CoV infection: A systematic review and meta-analysis. Leukemia 2020, 34, $1503-1511$. [CrossRef] [PubMed]

12. Luke, T.C.; Kilbane, E.M.; Jackson, J.L.; Hoffman, S.L. Meta-analysis: Convalescent blood products for Spanish influenza pneumonia: A future H5N1 treatment? Ann. Intern. Med. 2006, 145, 599-609. [CrossRef] [PubMed]

13. Davey, R.T.; Fernández-Cruz, E.; Markowitz, N.; Pett, S.; Babiker, A.G.; Wentworth, D.; Khurana, S.; Engen, N.; Gordin, F.; Jain, M.K.; et al. Anti-influenza hyperimmune intravenous immunoglobulin for adults with influenza A or B infection (FLU-IVIG): A double-blind, randomised, placebo-controlled trial. Lancet Respir. Med. 2019, 7, 951-963. [CrossRef]

14. Rojas, M.; Rodríguez, Y.; Monsalve, D.M.; Acosta-Ampudia, Y.; Camacho, B.; Gallo, J.E.; Rojas-Villarraga, A.; Ramírez-Santana, C.; Díaz-Coronado, J.C.; Manrique, R.; et al. Convalescent plasma in Covid-19: Possible mechanisms of action. Autoimmun. Rev. 2020, 19, 102554. [CrossRef]

15. Zhang, Y.; Xiao, M.; Zhang, S.; Xia, P.; Cao, W.; Jiang, W.; Chen, H.; Ding, X.; Zhao, H.; Zhang, H.; et al. Coagulopathy and antiphospholipid antibodies in patients with Covid-19. N. Engl. J. Med. 2020, 382, e38. [CrossRef] [PubMed]

16. Tang, N.; Bai, H.; Chen, X.; Gong, J.; Li, D.; Sun, Z. Anticoagulant treatment is associated with decreased mortality in severe Coronavirus disease 2019 patients with coagulopathy. J. Thromb. Haemost. 2020, 18, 1094-1099. [CrossRef]

17. Tang, N.; Li, D.; Wang, X.; Sun, Z. Abnormal coagulation parameters are associated with poor prognosis in patients with novel coronavirus pneumonia. J. Thromb. Haemost. 2020, 18, 844-847. [CrossRef]

18. Pruijssers, A.J.; George, A.S.; Schäfer, A.; Leist, S.R.; Gralinksi, L.E.; Dinnon, K.H.; Yount, B.L.; Agostini, M.L.; Stevens, L.J.; Chappell, J.D.; et al. Remdesivir inhibits SARS-CoV-2 in human lung cells and chimeric SARS-CoV expressing the SARS-CoV-2 RNA polymerase in mice. Cell Rep. 2020, 32, 107940. [CrossRef]

19. Yoo, J.H. Uncertainty about the efficacy of Remdesivir on COVID-19. J. Korean Med. Sci. 2020, 35, e221. [CrossRef]

20. Wiersinga, W.J.; Rhodes, A.; Cheng, A.C.; Peacock, S.J.; Prescott, H.C. Pathophysiology, transmission, diagnosis, and treatment of coronavirus disease 2019 (COVID-19): A review. JAMA 2020, 324, 782-793. [CrossRef] [PubMed]

21. Sharma, A.; Jaiswal, P.; Kerakhan, Y.; Saravanan, L.; Murtaza, Z.; Zergham, A.; Honganur, N.S.; Akbar, A.; Deol, A.; Franci, B.; et al. Liver disease and outcomes among COVID-19 hospitalized patients-A systematic review and meta-analysis. Ann. Hepatol. 2021, 21, 100273. [CrossRef]

22. Li, L.; Li, S.; Xu, M.; Yu, P.; Zheng, S.; Duan, Z.; Liu, J.; Chen, Y.; Li, J. Risk factors related to hepatic injury in patients with corona virus disease 2019. medRxiv 2020. [CrossRef]

23. Sahin, T.T.; Akbulut, S.; Yilmaz, S. COVID-19 pandemic: Its impact on liver disease and liver transplantation. World J. Gastroenterol. 2020, 26, 2987-2999. [CrossRef] [PubMed]

24. Altunisik, T.S.; Bayindir, Y.; Yilmaz, S.; Yalçınsoy, M.; Otlu, B.; Kose, A.; Sahin, T.T.; Akbulut, S.; Isik, B.; Başkiran, A.; et al Short-term experiences of a liver transplant centre before and after the COVID-19 pandemic. Int. J. Clin. Pract. 2021, 75 , e14668.

25. Hossain, M.; Tabassum, J.; Rahman, S.B.; Roy, U.; Mitra, S.; Rafi, M.; Islam, M.R.; Nesa, M.; Emran, T.B. Clinical Efficacy and Safety of Antiviral Drugs in the Extended Use against COVID-19: What We Know So Far. Biologics 2021, 1, 252-284. [CrossRef]

26. Sanders, J.M.; Monogue, M.L.; Jodlowski, T.Z.; Cutrell, J.B. Pharmacologic Treatments for Coronavirus Disease 2019 (COVID-19): A Review. JAMA 2020, 323, 1824-1836. [CrossRef] [PubMed]

27. Lepage, M.-A.; Rozza, N.; Kremer, R.; Grunbaum, A. Safety and effectiveness concerns of lopinavir/ritonavir in COVID-19 affected patients: A retrospective series. Clin. Toxicol. 2021, 59, 644-647. [CrossRef] [PubMed]

28. Parvathaneni, V.; Gupta, V. Utilizing drug repurposing against COVID-19-Efficacy, limitations, and challenges. Life Sci. 2020, 259, 118275. [CrossRef] [PubMed]

29. Marra, F.; Smolders, E.J.; El-Sherif, O.; Boyle, A.; Davidson, K.; Sommerville, A.J.; Marzolini, C.; Siccardi, M.; Burger, D.; Gibbons, S.; et al. Recommendations for Dosing of Repurposed COVID-19 Medications in Patients with Renal and Hepatic Impairment. Drugs RED 2021, 21, 9-27. 
30. Li, Y.; Xie, Z.; Lin, W.; Cai, W.; Wen, C.; Guan, Y.; Mo, X.; Wang, J.; Wang, Y.; Peng, P.; et al. An Exploratory Randomized Controlled Study on the Efficacy and Safety of Lopinavir/ritonavir or Arbidol Treating Adult Patients Hospitalized with Mild/moderate COVID-19 (ELACOI). medRxiv 2020. [CrossRef]

31. Wang, Y.; Zhang, D.; Du, G.; Du, R.; Zhao, J.; Jin, Y.; Fu, S.; Gao, L.; Cheng, Z.; Lu, Q.; et al. Remdesivir in Adults with Severe COVID-19: A Randomised, Double-Blind, Placebo-Controlled, Multicentre Trial. Lancet 2020, 395, 1569-1578. [CrossRef]

32. Zhai, G.; Li, M.; Wang, Y.; Jian, W. Drug-induced liver disturbance during treatment of Covid-19. Front. Pharmacol. 2021, 12, 719308. [CrossRef] [PubMed] 